\title{
Inflammatory Pseudotumour of the Jejunum Presenting As Intussusception
}

\author{
${ }^{1}$ Dr Murtuza Akhtar, MS, ${ }^{2}$ Dr Dipen Gandhi, MS, ${ }^{3}$ Dr Anne Wilkinson,MD, \\ ${ }^{4}$ Dr Kanhaiyalal Chandak,MS \\ ${ }^{1}$ Professor and Head, Surgery, ${ }^{2}$ Lecturer, Surgery, ${ }^{3}$ Associate Professor, Pathology, ${ }^{4}$ Lecturer, Surgery \\ NKP Salve Institute of Medical Sciences, Hingna, Nagpur 440019. MAHARASHTRA
}

\begin{abstract}
Inflammatory pseudotumour is a rare cause of intussusception. It consists of a localized, usually polypoid mass that is composed of inflammed fibrous and granulation tissue. ${ }^{[1]}$ We report a case of 42-year - old woman who presented with abdominal pain, vomiting and distention of abdomen since one day. $X$ ray abdomen (erect) did not show air fluid level. CT abdomen showed target sign suggestive of intussusception. Emergency exploratory laparotomy revealed jejuno-jejunal intussusception caused by a polypoidal mass. Resection and end to end anastomosis of jejunum was performed. Subsequent histopathology confirmed the mass to be an inflammatory pseudotumour of jejunum. Inflammatory pseudotumour of jejunum as a cause of intussusception has rarely been reported. Among adults presenting with obstruction, inflammatory pseudotumour should be considered in the differential diagnosis. Surgeons need to be aware of this condition because complete surgical excision is the treatment.
\end{abstract}

Key Words: Inflammatory Pseudotumour, Jejunum, Intussusception.

\section{Introduction}

Inflammatory pseudotumours [inflammatory myofibroblastic tumor], is a non neoplastic lesion that occurs most commonly in the lung. Among the extra pulmonary sites it may involve the gastrointestinal tract in which the stomach is commonly involved. However it also occurs in the ileum and rarely in the duodenum or jejunum. $^{[2]}$ It has a variable presentation in the gastrointestinal tract from asymptomatic, to small bowel obstruction due to intussusception.

Intussusception is the most common cause of bowel obstruction in children. On the other hand, only 5 to $10 \%$ of intussusceptions occur in adults, and it is a rare cause $(<1 \%)$ of adult bowel obstructions. Unlike in children, in whom more than $80 \%$ of episodes are idiopathic, in adult patients with intussusception, there is a demonstrable pathologic process acting as a lead point causing the condition in $80 \%$ to $90 \%$ of patients. This is usually due to benign or malignant neoplasms, trauma, post operative adhesions or Meckel's diverticulum. In the small intestine, benign neoplasms like lipoma, adenoma, neurofibroma can cause intussusception more often than malignant neoplasms. Inflammatory pseudotumour is an uncommon cause for adult intussusception.

\section{Case Report}

A 42 year old lady presented to a tertiary care hospital with complaints of abdominal pain, vomiting and abdominal distention since one day. Her general condition was fair but she had a pulse rate of $92 / \mathrm{min}$. She had a vague lump in the umbilical region which was tender. Per rectal examination was normal. The haematologoical and biochemical investigations were normal. Chest $\mathrm{x}$ ray was normal. $\mathrm{X}$ ray abdomen was noninformative. USG abdomen was normal. CT abdomen showed target sign suggestive of intussusception (Figure 1). Exploratory laparotomy was done. Jejuno-jejunal intussusception ( Figure 2) was seen around $40 \mathrm{~cm}$ from the duodenojejunal junction. The bowel was congested at the site of intussusception, and the rest of the length was healthy. Resection of the lump and end to end anastomosis of jejunum was done. On opening the specimen, a yellowish white polypoidal mass was seen in the lumen of the jejunum. It was a sessile polyp with a white and myxoid cut surface, measuring $3.5 \times 2.5 \times 2 \mathrm{~cm}$ ( Figure 3). Subsequent histopathology showed the polypoid mass to have an ulcerated mucosa. The polyp was predominantly composed of lymphocytes, few plasma cells, proliferating capillaries and occasional myofibroblasts, in an edematous fibrous stroma and was extending to the submucosa. Hence a histopathological diagnosis of inflammatory pseudotumour of the jejunum was made. Post operative recovery was uneventful. She was followed up for two years and found to be in good health. 


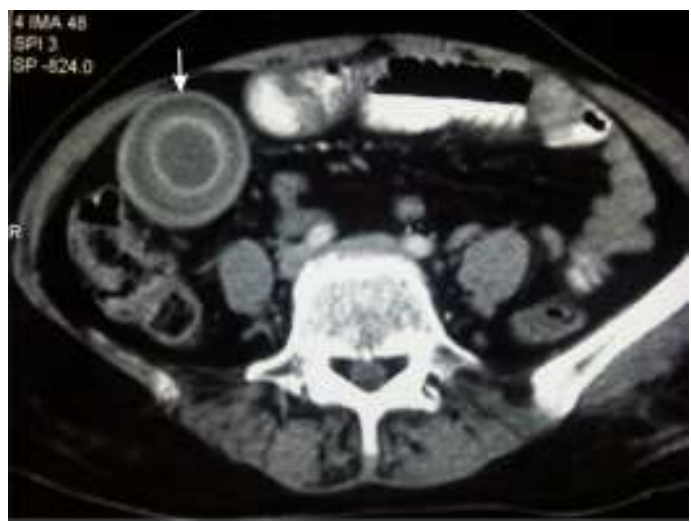

Figure 1. CT abdomen of patient showing target sign suggestive of intussusception

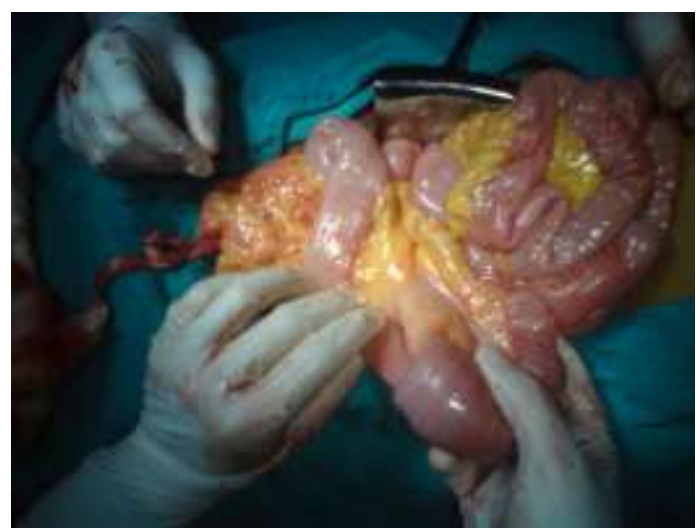

Figure 2. Intraoperative photograph showing intussusception of jejunum

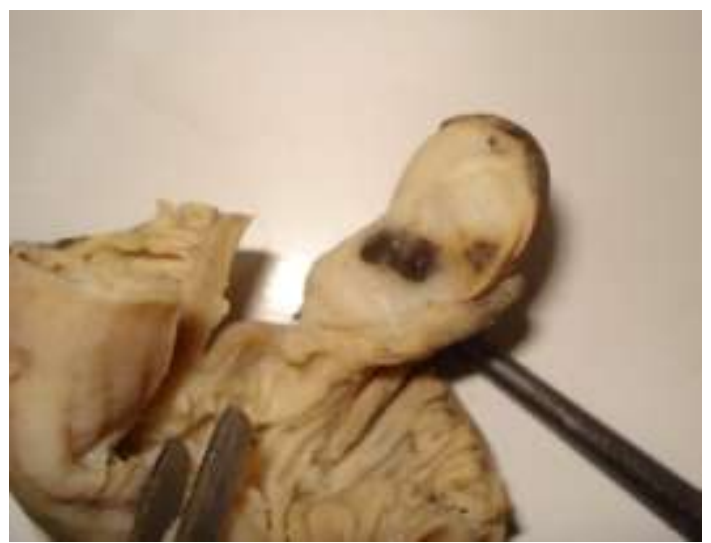

Figure 3. Gross specimen of resected jejunum with intraluminal submucosal polypoid mass

\section{Discussion}

Intussusception in adults is a rare cause for intestinal obstruction and is usually secondary to post operative adhesions, trauma, or neoplams. Inflammatory pseudotumour is a rare cause for intussusception. Many other terms have been used to refer to these lesions including inflammatory fibroid polyp, myofibroblastic tumour, Vanek's tumour and submucosal granuloma. ${ }^{[3]}$ Vanek described this tumour first in the gastrointestinal tract in 1949, where he called it an eosinophilic granuloma. " $\left.{ }^{4}\right]$ The term "inflammatory fibroid polyp" was proposed by Helwig and Ranier in 1953, to which have been added eosinophilic granuloma, hemangiopericytoma, fibroid polypoid, gastric fibroma with eosinophilic infiltration, eosinophilic polypoid granuloma, inflammatory pseudotumor and its pseudonym as Vanek polyp. ${ }^{[5]}$ They are typically found in the stomach, followed by the small and large intestine, and may rarely occur in the esophagus. Their occurrence in the jejunum is rare. ${ }^{[2]}$ They originate in the submucosa and typically appear as polyps or nodules. Histologically, the stroma in these lesions is characterized by lymphocytes and a variable eosinophil infiltration with proliferating spindle cells surrounding arborizing capillaries. The exact nature of the spindle cells remains controversial, ${ }^{[6]}$ however they are thought to be myofibroblasts. Loose myxoid fibrous tissue may also be seen. Inflammatory pseudotumours maybe associated with haematological abnormalities like increased ESR, 
leukocytosis, thrombocytosis and hypergammaglobulinemia, none of which were seen in the present case

Several theories have been proposed to describe the genesis of inflammatory pseudotumours. It has been suggested that they occur as a chronic inflammatory response to local noxious stimuli, with incomplete differentiation of myofibroblasts and primitive submucosal stromal cells. Others have suggested that the heavy eosinophilic infiltrate is in keeping with an uncontrolled allergic response. The large number of theories generated emphasizes the uncertain nature of the etiology. ${ }^{[7]}$

Although they may appear at any age, they are most common in the sixth and seventh decades, and have a male preponderance. Clinical symptoms depend on the location and size of the lesion. When they occur in the gastrointestinal tract, abdominal pain is the main symptom in patients whose lesions are in the stomach. Infrequently when located in the small intestine, pseudotumours present with obstruction as the initial symptom. Other symptoms such as vomiting, diarrhoea, bloody stools, tenesmus, and alteration in bowel habits are infrequent. ${ }^{[8-10]}$ Many inflammatory pseudotumours are identified incidentally during endoscopy or laparotomy. The ultrasonographic feature consists of heterogeneously hyperechoic mass and it should be included in the differential diagnosis of hyperechoic lesions of small bowel intussusception in adults. ${ }^{[1]}$

Preoperative diagnosis of inflammatory pseudotumour is often difficult, and confirmation can only be obtained by histological examination to differentiate them from malignancy. The treatment of inflammatory pseudotumour is surgical resection of the involved bowel. ${ }^{[12]}$ Surgical excision is curative in symptomatic patients, and recurrences are more common in lesions more than $8 \mathrm{~cm}$ size which are locally invasive. ${ }^{[13]}$

Jejunal inflammatory pseudotumour causing intussusception has been rarely reported. Preoperative diagnosis of inflammatory pseudotumour is often difficult, and confirmation can only be obtained by histological examination. The treatment of inflammatory pseudotumour is surgical resection of the involved bowel.

\section{Acknowledgement}

We thank the Dean of our Institute Dr S Dasgupta, for permitting us to publish this paper

\section{References}

[1] Samter TG, Alstott DF, Kurlander GJ. Inflammatory fibroid polyps of the gastrointestinal tract. A report of 3 cases, 2 occurring in children. Am J Clin Pathol 1966; 45: 420-36.

[2] Rehman S, Gamie -Z, Wilson TR, Coup A, Kaur G. Inflammatory fibroid polyp (Vanek's tumour), an unusual large polyp of the jejunum: a case report. Cases Journal 2009; 2:7152

[3] Talley NJ: Gut eosinophilia in food allergy and systemic and autoimmune diseases. Gastroenterol Clin North Am 2008;37:307-32.

[4] Vanek J. Gastric Submucosal Granuloma with Eosinophilic Infiltration. Am J Pathol 1949; 25: $397-411$.

[5] Fuentes GA, Suárez M, Osorno A, Jerkov J, Espitia F, Manauta J. Vanek's polyp or inflammatory fibroid polyp. A case report and review of the literature. Cir Cir 2011;79:242-45

[6] Feldman M. Friedman LS, Sleisenger MH, eds. Sleisenger \& Fordtran's Gastrointestinal and Liver Disease. $9^{\text {th }}$ ed. Philadelphia, WB Saunders Co; 2010.

[7] Cawich SO, Harding HE, Leake PA, Arthurs M: Inflammatory Polyp as a Lead Point for Jejunal Intussusception. The Internet Journal of Surgery. 2009 Volume 18 Number 2

[8] Johnstone JM, Morson BC. Inflammatory fibroid polyp of the gastrointestinal tract. Histopathology $1978 ; 2: 349-61$.

[9] 9. Shimer GR, Helwig EB. Inflammatory fibroid polyps of the intestine. Am J Clin Pathol 1984 ; 81 : 708-14.

[10] Bays D, Anagnostopoulos GK, Katsaounos E et al. Inflammatory fibroid polyp of the small intestine causing intussusception : a report of two cases. Dig Dis Sci $2004 ; 49: 1677-80$.

[11] Chiu HM, Wang HP, Lin MT, Wu MZ, Chin LW, Lin JT. Ultrasonographic diagnosis of inflammatory pseudotumor of the ileum complicating with intussusception: a case report. Hepatogastrenterology 003;50:1345-7.

[12] Zager JS, Shaw JP, Kaufman JP, DeNoto G. Three cases of small bowel intussusception in relation to a rare lesion: inflammatory fibrous polyps. Dig Surg. 2001;18(2):142-6.

[13] Sanders BM, West KW, Gingalewski C, Engum S, Davis M, Grosfeld JL. Inflammatory pseudotumor of the alimentary tract: Clinical and Surgical experience. Journal of Pediatric Surgery 2001; 36: 169-73. 